between the logarithm of spore content and the number of samples failing, but there is no relationship between total bacterial content, the thermoduric bacterial content and the spore content of raw millss. Therefore, it is not possible to assess the value of milk for sterilization purposes in terms of good and bad farm milk-production; a good raw milk, or one which pasteurizes satisfactorily, may not give a sterilized milk which will keep well. The source of the spore-forming organisms has not been ascertained with certainty, but they do not appear to be air-borne. Spores have been found in udder milk, presumably originating from straw bedding used. The hygiene of plant is of utmost importance, and steam sterilization is only effective if the plant has been thoroughly pre-cleaned.

The value of the antibiotic nisin in cheese manufacture was described by H. B. Hawley (Yeovil) in a paper on the development and uses of nisin. He deseribed how certain strains of Strep. lactis have been found to inhibit lactobacilli under given conditions, and investigations at the National Institute for Research in Dairying led to the discovery of nisin, which is produced by certain strains of the streptococcus. Nisin has a polypeptide structure, and there are several different known types. They have different antibacterial properties, and the types and proportions of each produced depend on the cultural conditions. Because of the particular value of nisin in inhibiting growth of $\mathrm{Cl}$. welchii, it has been used effectively in the controlling of cheese, and is particularly valuable with processed cheeses; experimental work is proceeding at present on sweet, lowacid cheeses. Nisin can also be used for control of flat-sour in canning and in the prescrvation of other foods, particularly meat products. There are numerous and unexpected problems associated with the use of nisin in cheeses because, for example, it upsets the general balance of the bacterial flora and so may produce a cheese of very different texture, odour and taste. Moreover, the presence of certain bacteria appears to nullify the effect of the nisin.

\section{CHARACTERISTICS OF THE BOTTOM ZONE OF LAKES}

A

SYMPOSIUM on "The Biological, Physical and Chemical Characteristics of the Profundal Zone of Lakes", organized by Prof. V. Tonolli, was held at the Istituto Italiano di Idrobiologia at Pallanza, Lago Maggiore, during July 21-24, under the auspices of the International Union of Biological Sciences with the financial aid of Unesco.

Many advances have been made in recent years in our knowledge of the physical conditions and chemical exchanges at the interface between mud and the bottom water of lakes, thanks to the development of various new techniques, and H. J. Elster (Germany), while emphasizing the services rendered to limnology by A. Thienemann's oligotropic-outropic classification of lake types, made it clear, using Black Forest lakes and Lake Constance as examples, that a rigid adherence to the classical type concept is not justified, particularly as the chemical turnover in the hypolimnion is to a considerable extent influenced by hydrographical factors. O. Steinböck (Austria) sup. ported this view by his thesis that in the case of upland lakes hydrographical factors are predominant : there are here no lake types but the waters have geographical characteristics, and are best classified as mountain lakes, perennial pools and temporary pools. In those of the second category, daily meteorological changes affect the whole depth of water, so that there is no stable layering. 'The oxygen content of the bottom water of the upland lakes depends not so much on the productivity of the lake as on organic material washed into it, so that a pseudo-eutropic condition may arise.

K. Strøm (Norway) and B. Dussart (France) dealt with certain little-known phenomena in the hypolimnion. The temperature of the bottom water with maximal density depends on pressure and hence is below $4^{\circ} \mathrm{C}$. in the depths of great lakes. The existence of supposed subaquatic springs is often doubtful, for direct observation, as in the Lac d'Annecy, can seldom be made, and their presence is usually deduced from temperature, bottom conditions and faunistic peculiarities; but it can be shown, for example in Lake Geneva, that the phenomena in question may be caused by special hydrographical conditions.

Exchanges at the mud surface were considered by F. Ruttner (Austria), who reported on a striking natural experiment in one of the lakes at Lunz which illustrates the provisional nature of lake types. This 3-metre deep spring-lake is characteristically oligotropic, with a sparse plankton and without thermal and chemical layering. In autumn, however, after dry weather, considerable quantities of lime become dissolved as a result of the decay of the macroflora. The resulting solution of a higher specifie gravity flows down into the now inactive funnel of the spring, giving a eutropic zonation, with the disappearance of oxygen, formation of hydrogen sulphide and development of an oligoaerobic plankton. The great extent of mud surface relative to water volume is largely responsible for the very considerable chemical exchanges, with a paucity of oxygen. Such exchanges also take place between water and dissolved colloidal substances, particularly humus. This is an important phenomenon in peaty waters, where the colloids, acting as cation and anion exchangers, control the ionic composition. W. Ohle (Germany) gave a good example of such an action in the case of a magnesium-calcium ratio which was $1: 2$ in electrolyte-poor water and as much as $1: 7$ in water rich in electrolytes.

Sedimentation studies were described by Mrs. W. Tutin (Great Britain) and E. Thomas (Switzerland). The latter has made a quantitative investigation of organic and inorganic sediments in various Swiss lakes, comparing oligotropic with eutropic conditions, considering in particular the nitrogen and phosphorus balance between mud and water in relation to production.

On the faunistic side, H. Järnefelt (Finland) came to the conclusion, from extensive studies of Finnish lakes, that no single factor studied up to the present can account for the nature of populations : a complex of causes must be involved. F. Lenz (Germany) supported this thesis with reference to the bottom fauna of the Lago Maggiore, which varies with meteorological and consequent hydrographical conditions. Contributions to a knowledge of these conditions were made by $N$. Della Croce and $O$. Ravera (Italy). The former has investigated oligochrte populations, the density of which depends in part on the particle size of the sediments. Ravera made an experimental study of the quantity of excrement produced in unit time by members of 
the three oligochæte species of the lake bottom; characteristic differences were found, depending both on species and depth. G. P. Moretti (Italy) made, in the same connexion, a quantitative study of the cases of caddis larva, some found as deep as $300 \mathrm{~m}$.

I. Findenegg (Austria) reported on the bottom faunas of lakes in the Kärntner region, which are known to limnologists for the frequent occurrence of the so-called meromictic lake type. It was found that the density of the bottom fauna was at least as great in oligotrophic as in eutrophic lakes. This is due to the low oxygen content of the eutrophic hypolimnion and to the greater vertical range of plankton in the transparent oligotropic waters and consequent greater fall of food material to the bottom.

A particularly interesting faunistic situation from the evolutionary point of view is provided by Lake Ochrida, on which S. Stankovič (Jugoslavia) spoke. This pre-Glacial lake has a hypolimnion with a constant temperature throughout the year, and an endemic profundal fauna, with sub-species the nearest relatives of which inhabit the littoral zone, from which they are clearly derived.

Other valuable contributions were made by $\mathrm{E}$. S. Deevey and D. G. Frey (United States) and by $\mathbf{H}$. Züllig (Switzerland). A detailed report of the symposium will be obtainable from the Secretary of the International Union of Biological Sciences, Laboratoire de Physiologie Végétale, Sorbonne, Paris, or from the Istituto Italiano di Idrobiologia, Pallanza, Italy.

R. A. Vollenweider

\section{THE IONOSPHERE DURING THE SOLAR ECLIPSE OF FEBRUARY 25, 1952}

\author{
By C. M. MINNIS \\ Radio Research Station (Department of Scientific and \\ Industrial Research), Slough
}

$\mathrm{D}$ URING the past twenty years, an intensive study has been made of the response of the ionized layers of the earth's upper atmosphere to changes in the intensity of the solar radiation incident on them. Most of the existing fund of knowledge on this subject has been built up from observations of the variations in ionospheric parameters which result from the diurnal and annual changes in radiation intensity caused by the rotation of the earth about its axis and around the sun. The slowness of these changes and the superposed perturbations arising from imperfectly understood largescale tidal effects lead to difficulties in the analysis of such data.

An eclipse of the sun may be thought of as providing the conditions for a controlled experiment in the ionosphere during which a rapid change in the intensity of the incident radiation takes place but which is not, to a first approximation, further complicated by the normal diurnal changes. Ionospheric observations have, for this reason, been made during solar eclipses on many occasions since the first indirect measurements of Eccles ${ }^{1}$ in 1919; but, since the end of the Second World War, few suitable opportunities have occurred of using modern ionospheric sounding techniques in this way. The totality belt for the 1952 eclipse extended from West
Africa across the Anglo-Egyptian Sudan to Persia and was, in consequence, fairly accessible. The Department of Scientific and Industrial Research sent two expeditions to Central Africa: one to Ibadan, near Lagos, where the eclipse was partial, and another to Khartoum in the totality belt. At both stations measurements of the height and electron density of the ionospheric layers were made during the eclipse and during the control periods preceding and following it. In addition, observations were made at the Radio Research Station at Slough and at its outstations at Inverness and Singapore, all of which were near the edge of the eclipse area.

\section{E- and Fl-Layers}

The sudden reversal in the rate of change of the radiation intensity during a total or near total eclipse ought, in principle, to make possible the calculation of the effective recombination coefficients which are measures of the rate of decay of ionization in the different layers. For the application of this technique in its simplest form, a necessary condition is that the ionizing radiation should be emitted uniformly from the whole of the sun's disk. Unfortunately, the character of the changes in electron density which are actually observed during eclipses casts considerable doubt on the validity of this assumption. For the 1940 eclipse, Higgs ${ }^{2}$ found it to be untenable and a.tempted to explain his results by assuming that the radiation was emitted from four known areas of calcium flocculi in addition to a component assumed to come from a uniformly radiating disk. The best fit with the observed densities in the $E_{\text {-layer was }}$ obtained when the intensity of the disk component was put equal to zero ; but, as Higgs himself points out, this is not a unique solution. It seems likely that the best fit was not the true one in this instance, particularly since the corresponding results for the F'-layer indicated a very large contribution from the disk.

Waldmeier suspected that the $E$-layer measurements made by Rydbeck during the 1945 eclipse might be consistent with the assumption that the ionizing radiation originated in those parts of the inner corona in which the emission line at $5303 \mathrm{~A}$. was strong; a comparison of the ionospheric data with a contour map of the intensity of the $5303 \mathrm{~A}$. line confirmed this ${ }^{3}$. A similar comparison between the ionospheric data obtained at Khartoum in 1952 and the coronal contours based on measurements made at the Pic du Midi tended to support Waldmeier's conclusion, although an unexplained discrepancy remained 4 .

A later examination of the Khartoum data for the $E$-layer has shown that the distribution and relative intensities of the sources of radiation can, for this eclipse, be deduced with some precision from the ionospheric data alone, without the need for making any assumptions concerning the positions of the sources. The discrepancy mentioned earlier is then seen to be due to the existence of an intense narrow source on the west limb of the sun, the evidence for which on the coronal intensity map is not decisive. Confirmation of the positions and relative intensities of the sources, as deduced from the Khartoum results, has been obtained by applying a similar method of analysis to $E$-layer data obtained by Piggott ${ }^{5}$ at Ibadan two hours earlier (Table I).

Data on the sources of $5303 \mathrm{~A}$. are given in Table 2. While there is an obvious similarity between 